\title{
BMJ Open Prevalence and differentials of overweight and obesity in preschool children in Sub-Saharan Africa
}

\author{
Samson Gebremedhin
}

To cite: Gebremedhin S. Prevalence and differentials of overweight and obesity in preschool children in SubSaharan Africa. BMJ Open 2015;5:e009005.

doi:10.1136/bmjopen-2015009005

- Prepublication history and additional material is available. To view please visit the journal (http://dx.doi.org/ 10.1136/bmjopen-2015009005)

Received 8 June 2015 Revised 25 November 2015 Accepted 27 November 2015

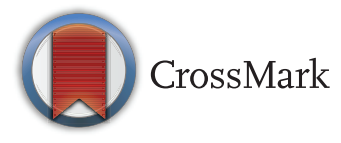

School of Public and Environmental Health, Hawassa University, Hawassa, Ethiopia

Correspondence to Dr Samson Gebremedhin; samsongmgs@yahoo.com

\section{ABSTRACT}

Objective: To determine the prevalence and differentials of overweight/obesity (body mass index (BMI)-for-age z-score $>2$ ) in preschool children in SubSaharan Africa (SSA).

Design: Cross-sectional study.

Setting: The study was conducted on the basis of the data of 26 Demographic and Health Surveys carried out in SSA since 2010.

Participants: The records of 155726 children aged 0-59 months were included in the analysis.

Primary outcome: Overweight/obesity.

Results: The prevalence of overweight/obesity was $6.8 \%$ (95\% $\mathrm{Cl} 6.7 \%$ to $6.9 \%$ ). Among the countries represented, higher figures were reported in Sierra Leone (16.9\%), Comoros (15.9\%) and Malawi $(14.5 \%)$, whereas lower prevalence was found in Ethiopia (3.0\%), Togo (2.6) and Senegal (2.0\%). In 11 of the countries, overweight/obesity was more prevalent than wasting. It is estimated that in the whole subcontinent, 10.7 million children were affected by the problem. The prevalence of overweight/obesity was slightly higher in boys than in girls. Overweight/obesity was three times more frequent in stunted children than in normal children. The risk also significantly increased with increasing maternal BMI and birth weight and decreased with increasing maternal age, maternal education, child's age and number of siblings. On the other hand, no significant association was observed with national gross domestic product per capita, place of residence (urban-rural) and household wealth index. Conclusion: Childhood overweight/obesity has become a sizeable problem in the subcontinent.

\section{INTRODUCTION}

Obesity is a major risk factor for several noncommunicable diseases including diabetes, cardiovascular diseases and cancers. ${ }^{1}$ In 2010, overweight and obesity were estimated to cause 3.4 million deaths and $3.9 \%$ of years of life lost. ${ }^{2}$ Globally, since 1980, the combined prevalence has increased by $27.5 \%$ for adults and $47.1 \%$ for children. ${ }^{3}$ In the same period, the number of overweight and obese individuals increased from 857 million to 2.1 billion. $^{3}$

\section{Strengths and limitations of this study}

- The analysis was done on the basis of a large sample $(>150000)$ of children representative of 26 countries in the region.

- The study provides recent information as all the surveys included in the analysis had been conducted within the past 5 years.

- All countries in the subcontinent are not represented.

- Birth weight data were based on recall by mothers.

- Since the original surveys were cross-sectional, causal inference is not viable.

Obesity in preschool children is a growing problem and it is receiving increasing attention. In 2010, 43 million children were overweight/obese and the combined figure is expected to reach 60 million in $2020 .{ }^{4}$ The prevalence also increased from $4.2 \%$ in 1990 to $6.7 \%$ in 2010 . Childhood obesity causes a wide range of consequences including increasing the risk of premature illness and death later in life. ${ }^{4}$ According to a study, children who are obese as early as 2 years of age are likely to be obese as adults. ${ }^{5}$

Obesity is an increasing concern in the developing world. ${ }^{6}{ }^{7}$ Since 1980 , the number of overweight and obese adults in the developing world has quadrupled to around one billion. ${ }^{8}$ In developing countries, between 1980 and 2013, the combined prevalence in children and adolescents increased from $8 \%$ to $13 \%$ both for boys and girls. ${ }^{3}$ In preschoolers, the estimated prevalence in Africa increased from $4.0 \%$ in 1990 to 8.5 in 2010 . This trend is expected to reach $12.7 \%$ in 2020. Similarly, in Asia, the figure has increased from $3.2 \%$ to $4.9 \%{ }^{4}$

In the developing world, infectious diseases and undernutrition remain unresolved public health concerns. Nevertheless, noncommunicable diseases related to overnutrition and sedentary lifestyle are also on the rise, witnessing the ongoing rapid nutrition 
and epidemiological transitions. ${ }^{6}{ }^{9}$ The transitions are attributable to several socioeconomic and demographic changes. ${ }^{10}$

The present analysis describes the prevalence and differentials of overweight/obesity in preschool children in 26 Sub-Saharan Africa (SSA) countries. It also estimates the number of children affected by the problem in the whole region.

\section{METHODS AND MATERIALS \\ Study setting}

SSA consists of 49 of Africa's 55 states that are fully or partially located south of the Sahara desert. The region is the most underdeveloped part of the world with a gross domestic product (GDP) per capita of US $\$ 2235$. $^{11}$ As of 2011, 40, 21 and 9\% of children younger than 5 years in SSA were stunted, underweight and wasted, respectively. ${ }^{12}$

\section{Study design}

A cross-sectional study based on the secondary data of 26 Demographic and Health Surveys (DHSs) was conducted in the region between 2010 and 2014 (table 1).

\section{Inclusion and exclusion DHS surveys}

All standard DHSs conducted since 2010 in the region were considered for the study. The Equatorial Guinea-

Table 1 List of 26 surveys included in the analysis, Sub-Saharan Africa, 2010-2014

\begin{tabular}{llr}
\hline Country & $\begin{array}{l}\text { Year of data } \\
\text { collection }\end{array}$ & \multicolumn{1}{c}{$\begin{array}{c}\text { Sample } \\
\text { size }\end{array}$} \\
\hline Burundi & 2010 & 3493 \\
Burkina Faso & 2010 & 6723 \\
Cameroon & 2011 & 5185 \\
Comoros & 2012 & 2699 \\
Congo Brazzaville & $2011 / 2012$ & 4531 \\
Congo Democratic Republic & $2013 / 2014$ & 8391 \\
Ethiopia & 2011 & 9880 \\
Gabon & 2012 & 3482 \\
Gambia & 2013 & 3360 \\
Guinea & 2012 & 3216 \\
Ivory Coast & $2011 / 2012$ & 3294 \\
Liberia & 2013 & 3259 \\
Malawi & 2010 & 4829 \\
Mali & $2012 / 2013$ & 4591 \\
Mozambique & 2011 & 9721 \\
Namibia & 2013 & 1845 \\
Niger & 2012 & 5123 \\
Nigeria & 2013 & 26758 \\
Rwanda & 2010 & 4116 \\
Senegal & $2010 / 2011$ & 6062 \\
Sierra Leone & 2013 & 4698 \\
Tanzania & 2010 & 6948 \\
Togo & $2013 / 2014$ & 3228 \\
Uganda & 2011 & 4212 \\
Zambia & $2013 / 2014$ & 11677 \\
Zimbabwe & $2010 / 2011$ & 4405 \\
\hline
\end{tabular}

2011 survey was not included as the data set was not available in the public domain. The Benin-2011-2012 survey was excluded due to concerns regarding the quality of the anthropometry data.

\section{Data extraction}

For all of the surveys, the 'child record' data set was downloaded from the Measure DHS website. All the surveys included boys and girls, and age ranged from 0 to 59 months. Child and maternal anthropometric data and various sociodemographic variables were extracted from the data sets. The extracted sociodemographic variables were: maternal age, educational status, place of residence, household wealth index (a composite measure of a household's cumulative living standard), child's age, sex, birth order and number of siblings. Individual records that had incomplete or implausible anthropometric data were excluded. GDP per capita of the counties was determined on the basis of the 2010 2014 World Bank estimate. ${ }^{13}$

\section{Sample size}

A total of 155726 children $0-59$ months of age were included in the analysis. The adequacy of the sample size for each country for estimating the prevalence of overweight/obesity was appraised using the single proportion sample size calculation formula. In the country that has the lowest sample size, that is, Comoros, the sample size was sufficient to estimate the expected prevalence of $8.5 \%^{4}$ with $95 \%$ confidence level, $1.5 \%$ margin of error and design effect of 2. In the other countries, the sample size allows for a smaller margin of errors. The study also had adequate power $(>90 \%)$ for identifying differentials of overweight/obesity.

\section{Sampling technique used in DHSs}

The DHS study is typically designed to generate a representative sample at the national (urban and rural) and regional/state levels. The survey applies a stratified twostage cluster sampling procedure. Initially, the study country would be stratified on the basis of the place of residence (urban/rural) and subnational administrative regions. Then, from each stratum, a predetermined number of enumeration areas (EAs) would be selected using the probability proportional to size technique. Finally, after conducting a complete household listing, fixed numbers of households would be sampled from EAs using the systematic random sampling technique. ${ }^{14}$

\section{Data collection in DHSs}

DHS data were collected by trained interviewers, supervisors and field editors. In all of the surveys, an intensive training lasting for 3-4 weeks was provided. Data were gathered using pretested and standard questionnaires prepared in the major local languages. The variables included in the current study were consistently measured across all surveys. Surveys followed standard procedures of anthropometric measurements. ${ }^{15}$ 


\section{Data management and analysis}

Data management and analysis were conducted using SPSS and STATA packages. For each of the countries, the data set was downloaded and merged into a single data set. All statistical indicators were computed using weighted analysis that considered the sampling weight and the population size of the countries.

Z-scores for body mass index (BMI)-for-age and height-for-age (HFA) were generated on the basis of the WHO growth reference data. Children with z-scores for BMI-for-age greater than 3 and 2 to 3 were considered as obese and overweight, respectively. Children with z-scores for HFA less than-2 and -2 to 2 were defined as stunted and normal, respectively.

The number of children affected by overweight/ obesity was estimated for each country on the basis of the prevalence of overweight/obesity, population size ${ }^{16}$ and proportion of children younger than 5 years. ${ }^{17}$ Overweight/obesity-to-wasting ratio was calculated by dividing the prevalence of overweight/obesity to prevalence of wasting.

The association between overweight/obesity and various factors was assessed using a mixed effects binary logistic regression model. The final model included one country level variable (GDP per capital) and several individual level variables. The outputs of the analysis are presented using adjusted OR (AOR). The association between stunting and overweight/obesity has not been adjusted for other variables, as stunting can act as a potential mediator for many of the sociodemographic variables considered in the study.

\section{Ethical considerations}

The data sets were accessed after obtaining permission from the DHS programme. The primary data were collected in line with international ethical guidelines.

\section{RESULTS}

\section{Sociodemographic characteristics}

Data from 26 countries that constitute $70.8 \%$ of the total SSA population were represented in the study and a total of 155726 children aged 0-59 months were included in the analysis. Their mean age $( \pm \mathrm{SD})$ was 28.1 $( \pm 17.2)$ months and the male-to-female ratio was 1.02 . About a quarter $(28.4 \%)$ of the children were sampled from urban areas. The mean maternal age was 29.1 $( \pm 6.9)$ years and the median number of children ever born to them were four with an IQR of 4 . About half $(47.6 \%)$ of the respondents were literate.

\section{Prevalence of childhood obesity and overweight}

The weighted prevalence of overweight and obesity was $3.9 \%(95 \%$ CI $3.8 \%$ to $4.0 \%$ ) and $2.9 \%$ (95\% CI $2.8 \%$ to $3.0 \%)$, respectively, whereas the combined prevalence was $6.8 \%$ (95\% CI $6.7 \%$ to $6.9 \%$ ). Among the countries represented in the study, higher prevalence rates of overweight/obesity were reported in Sierra Leone (16.9\%),
Comoros (15.9\%) and Malawi (14.5\%), whereas lower figures were found in Ethiopia (3.0\%), Togo (2.6) and Senegal $(2.0 \%)$ (table 2).

\section{Estimated number of obese and overweight children}

Assuming that the prevalence of overweight and obesity in the SSA region is comparable to that in the studied countries, the number of affected children was estimated. Accordingly, in the 2010-2014 period, there were 4.6 million obese and 6.1 million overweight children in the region. Among the studied countries, the numbers of overweight/obese children were higher in Nigeria (2.3 million), DR Congo (0.9 million), Tanzania (0.6 million) and Mozambique (0.5 million).

\section{Overweight-to-wasting ratio}

Classification based on BMI-for-age showed that $11.1 \%$ of the children were wasted ( $\mathrm{z}$ score less than -2.0 ). Accordingly, in the subcontinent, for every wasted child approximately 0.6 obese/overweight children exist. In 11 of the 26 countries studied, overweight/obesity was more prevalent than wasting. In countries like Malawi and Rwanda, the combined prevalence of overweight and obesity was more than three times higher than that of wasting (figure 1).

\section{Sociodemographic differentials of overweight/obesity}

The prevalence of overweight/obesity was slightly higher in boys than in girls with an OR of 1.15 (95\% CI 1.10 to 1.20). The gender difference was consistent across all age groups (data not shown). When compared to children aged 0-5 months, children aged 6-23 and 2459 months had 29 and $32 \%$ reduced odds of overweight/obesity, respectively.

Regarding maternal educational status, taking children born to mothers with secondary or above level of education as the reference, children born to mothers with no formal education and with primary level education had 1.23 (95\% CI 1.15 to 1.32 ) and 1.10 (95\% CI 1.03 to 1.17) times increased odds. First order births, as compared with a birth order of five or more, had 25\% reduced odds of overweight/obesity. Risk of overweight/ obesity consistently increased with decreasing maternal age and number of siblings.

Nevertheless, obesity/overweight was not significantly associated with GDP per capita of the countries, place of residence and household wealth index (table 3). Data on the relationship between GDP per capital and overweight/obesity are given in online supplementary table S1.

Birth weight, stunting and maternal BMI as differentials of childhood overweight/obesity

Maternal and childhood overweight/obesity showed a significant association. Obese/overweight mothers had $1.50(95 \%$ CI 1.42 to 1.58$)$ times increased odds of having an overweight/obese child. When compared to 
Table 2 Prevalence of overweight and obesity in preschool children and number of children affected in 26 Sub-Saharan countries, 2010-2014

\begin{tabular}{|c|c|c|c|c|c|c|}
\hline \multirow[b]{2}{*}{ Country } & \multicolumn{3}{|c|}{ Prevalence (\%) } & \multicolumn{3}{|c|}{ Number of children affected } \\
\hline & Obesity & Overweight & Total & Obesity & Overweight & Total \\
\hline Sierra Leone & 9.5 & 7.4 & 16.9 & 100130 & 77996 & 178126 \\
\hline Comoros & 9.8 & 6.4 & 16.2 & 12544 & 8192 & 20736 \\
\hline Malawi & 5.8 & 8.7 & 14.5 & 170172 & 255258 & 425430 \\
\hline Mozambique & 4.2 & 7.7 & 11.9 & 183708 & 336798 & 520506 \\
\hline Gabon & 3.7 & 6.0 & 9.8 & 7104 & 11520 & 18816 \\
\hline Rwanda & 2.3 & 7.4 & 9.7 & 43401 & 139638 & 183039 \\
\hline Cameroon & 2.8 & 6.5 & 9.3 & 96320 & 223600 & 319920 \\
\hline Zambia & 3.4 & 5.4 & 8.8 & 82076 & 130356 & 212432 \\
\hline Zimbabwe & 3.0 & 5.5 & 8.5 & 50700 & 92950 & 143650 \\
\hline Nigeria & 4.1 & 3.7 & 7.8 & 1209992 & 1091944 & 2301936 \\
\hline Tanzania & 2.6 & 4.5 & 7.2 & 229788 & 397710 & 636336 \\
\hline DR Congo & 2.7 & 3.8 & 6.5 & 364743 & 513342 & 878085 \\
\hline Namibia & 2.3 & 3.7 & 6.0 & 6624 & 10656 & 17280 \\
\hline Uganda & 1.3 & 4.7 & 6.0 & 95940 & 346860 & 442800 \\
\hline Guinea & 2.5 & 3.2 & 5.7 & 50150 & 64192 & 114342 \\
\hline Niger & 3.5 & 2.2 & 5.7 & 118300 & 74360 & 192660 \\
\hline Gambia & 3.4 & 2.0 & 5.4 & 10336 & 6080 & 16416 \\
\hline Mali & 2.2 & 2.8 & 5.0 & 64790 & 82460 & 147250 \\
\hline Liberia & 1.7 & 3.1 & 4.8 & 14212 & 25916 & 40128 \\
\hline Congo Brazzaville & 1.3 & 3.5 & 4.7 & 9152 & 24640 & 33088 \\
\hline Burundi & 1.5 & 3.2 & 4.6 & 29430 & 62784 & 90252 \\
\hline Burkina Faso & 1.9 & 2.6 & 4.4 & 61560 & 84240 & 142560 \\
\hline Ivory Coast & 1.2 & 2.9 & 4.1 & 37980 & 91785 & 129765 \\
\hline Ethiopia & 1.3 & 1.7 & 3.0 & 197132 & 257788 & 454920 \\
\hline Togo & 0.9 & 1.7 & 2.6 & 8928 & 16864 & 25792 \\
\hline Senegal & 0.8 & 1.3 & 2.0 & 17280 & 28080 & 43200 \\
\hline $\mathrm{SSA}^{*}$ & 2.9 & 3.9 & 6.8 & 4576224 & 6126209 & 10702433 \\
\hline
\end{tabular}

${ }^{*}$ Estimated for the whole SSA region.

SSA, Sub-Saharan Africa.

normal children, stunted children were $3.86(95 \%$ CI 3.70 to 4.04$)$ times more likely to be overweight/obese.

In DHSs, birth weight of children is assessed on the basis of the mother's recall. Almost half $(44.7 \%)$ of the respondents included in this study reported the birth weight of their babies. In the remaining cases, the baby was either not weighed at birth or the respondent did not manage to recall it. The risk of childhood
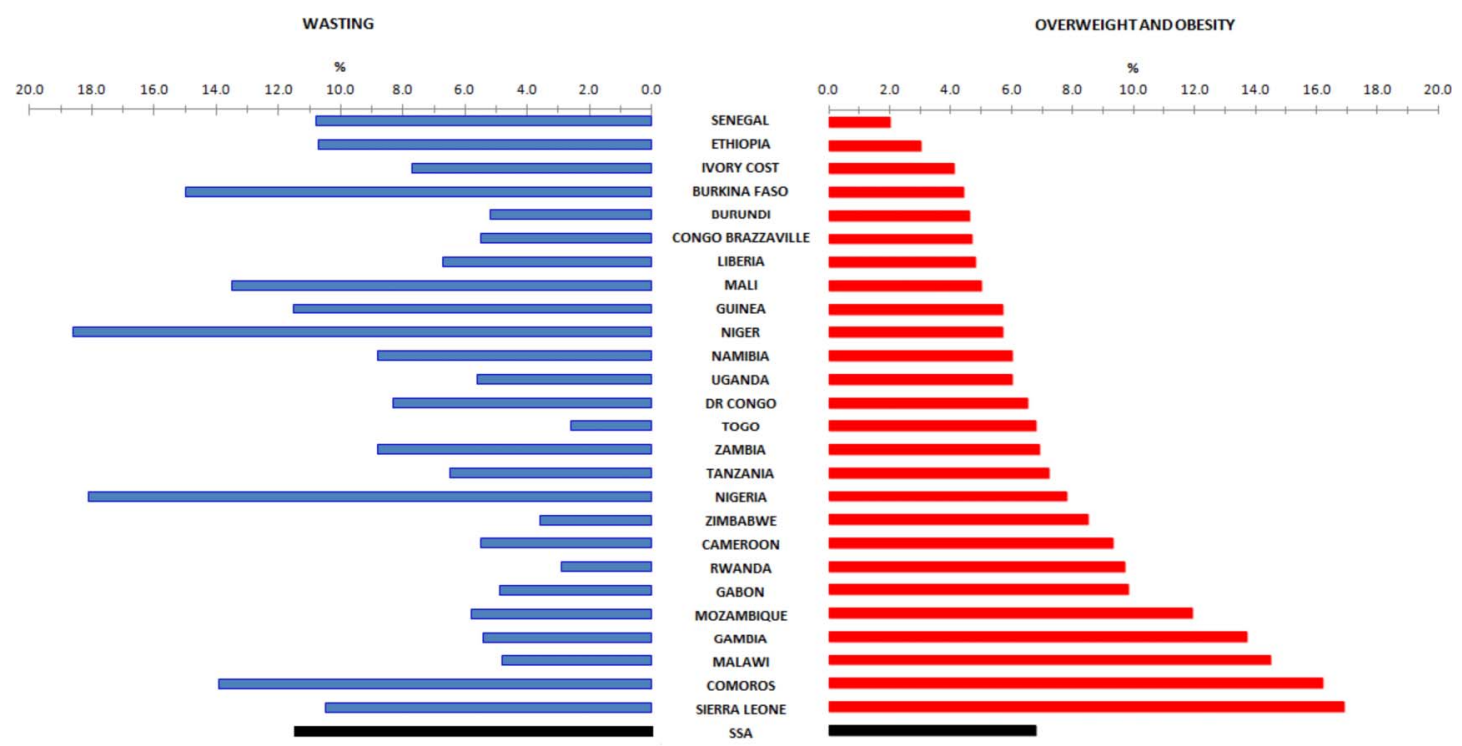

Figure 1 Prevalence of overweight/obesity and wasting in preschool children in 26 Sub-Saharan African Countries, 2010-2014. 
Table 3 Sociodemographic differentials of overweight and obesity in 26 Sub-Saharan countries, 2010-2014

\begin{tabular}{|c|c|c|}
\hline Variables & $\begin{array}{l}\text { Prevalence of } \\
\text { overweight/ } \\
\text { obesity }\end{array}$ & AOR $^{*}$ \\
\hline \multicolumn{3}{|l|}{ Sex } \\
\hline Male & 7.1 & $1.15(1.10 \text { to } 1.20)^{*}$ \\
\hline Female & 6.4 & $1 \dagger$ \\
\hline \multicolumn{3}{|c|}{ Child age (months) } \\
\hline $0-5$ & 9.1 & $1 †$ \\
\hline $6-23$ & 6.9 & $0.71(0.67$ to 0.76$) \neq$ \\
\hline 24-59 & 6.3 & $0.68(0.64$ to 0.72$) \ddagger$ \\
\hline \multicolumn{3}{|c|}{ Place of residence } \\
\hline Urban & 6.8 & $0.98(0.92$ to 1.04$)$ \\
\hline Rural & 6.8 & $1 \dagger$ \\
\hline \multicolumn{3}{|l|}{ Wealth index } \\
\hline Lowest & 7.2 & $1.05(0.97$ to 1.15$)$ \\
\hline Second & 6.8 & 1.03 (0.94 to 1.12$)$ \\
\hline Middle & 6.9 & $1.01(0.93$ to 1.10$)$ \\
\hline Fourth & 6.4 & 1.01 (0.93 to 1.08$)$ \\
\hline Highest & 6.6 & $1 \dagger$ \\
\hline \multicolumn{3}{|c|}{ Maternal educational status } \\
\hline Illiterate & 6.5 & $1.23(1.15$ to 1.32$) \neq$ \\
\hline Primary & 7.0 & $1.10(1.03$ to 1.17$) \ddagger$ \\
\hline $\begin{array}{l}\text { Secondary or } \\
\text { above }\end{array}$ & 7.0 & $1 \dagger$ \\
\hline \multicolumn{3}{|c|}{ Maternal age (years) } \\
\hline$<25$ & 7.9 & $1.22(1.13$ to 1.33$) \ddagger$ \\
\hline $25-34$ & 6.5 & $1.08(1.01$ to 1.14$) \ddagger$ \\
\hline$>34$ & 6.2 & $1 \dagger$ \\
\hline \multicolumn{3}{|c|}{ Number of siblings } \\
\hline 0 & 8.1 & $1.56(1.30$ to 1.87$) \ddagger$ \\
\hline 1 & 7.0 & $1.31(1.13$ to 1.51$) \ddagger$ \\
\hline 2 & 7.2 & $1.17(1.05$ to 1.31$) \ddagger$ \\
\hline 3 or more & 6.3 & 1 \\
\hline \multicolumn{3}{|l|}{ Birth order } \\
\hline 1 & 7.3 & $0.75(0.63$ to 0.90$) \ddagger$ \\
\hline 2 & 7.2 & 0.89 (0.77 to 1.02$)$ \\
\hline 3 & 7.3 & 0.99 (0.89 to 1.10$)$ \\
\hline 4 & 6.0 & 1.01 (0.94 to 1.08$)$ \\
\hline 5 or more & 6.4 & $1 \dagger$ \\
\hline $\begin{array}{l}\text { GDP per capita } \\
(\text { US\$)§ }\end{array}$ & - & $1.00(0.96$ to 1.04$)$ \\
\hline \multicolumn{3}{|c|}{$\begin{array}{l}\text { *Adjusted for maternal BMI and all variables in the table. } \\
\text { †Set as the reference group. } \\
\text { †Significant association at } 95 \% \text { confidence level. } \\
\text { §Entered as a continuous variable. } \\
\text { AOR, adjusted OR; BMI, body mass index; GDP, gross domestic } \\
\text { product. }\end{array}$} \\
\hline
\end{tabular}

overweight/obesity was significantly higher among macrosomic babies (AOR=1.24, 95\% CI 1.15 to 1.34) and lower in low birthweight (LBW) babies $(\mathrm{AOR}=0.79$, $95 \%$ CI 0.71 to 0.88 ) (table 4 ).

\section{DISCUSSION}

The study concluded that in many of the countries included in the study, the prevalence of overweight/ obesity is substantially high. Even in some countries, overnutrition is more common than undernutrition.
Table 4 Birth weight, stunting and maternal BMI as differentials of childhood overweight/obesity in 26 Sub-Saharan countries, 2010-2014

\begin{tabular}{|c|c|c|}
\hline Variables & $\begin{array}{l}\text { Prevalence of } \\
\text { overweight/ } \\
\text { obesity }\end{array}$ & OR $(95 \% \mathrm{Cl})^{\star}$ \\
\hline \multicolumn{3}{|l|}{ Maternal BMI $\left(\mathrm{kg} / \mathrm{m}^{2}\right)$} \\
\hline$\leq 24.5$ & 6.3 & $1 \dagger$ \\
\hline$>25.0$ & 9.2 & $1.50(1.42$ to 1.58$) \ddagger$ \\
\hline \multicolumn{3}{|l|}{ Birth weight } \\
\hline $\begin{array}{l}\text { Low birth weight } \\
(<2.5 \mathrm{~kg})\end{array}$ & 5.9 & $0.79(0.71$ to 0.88$) \ddagger$ \\
\hline $\begin{array}{l}\text { Normal birth } \\
\text { weight } \\
(2.5-3.9 \mathrm{~kg})\end{array}$ & 7.4 & $1 \dagger$ \\
\hline $\begin{array}{l}\text { High birth weight } \\
(\geq 4.0 \mathrm{~kg})\end{array}$ & 8.2 & $1.24(1.15$ to 1.34$) \ddagger$ \\
\hline \multicolumn{3}{|l|}{ Stunting } \\
\hline $\begin{array}{l}\text { Stunted } \\
(<-2 \text { z score })\end{array}$ & 12.1 & $3.86(3.70$ to 4.04$) \ddagger$ \\
\hline $\begin{array}{l}\text { Normal ( } z \text { score } \\
\text { between-2 and 2) }\end{array}$ & 3.4 & $1 \dagger$ \\
\hline \multicolumn{3}{|c|}{$\begin{array}{l}\text { *The associations with birth weight and maternal BMI were } \\
\text { adjusted for all independent variables listed in table 3; however, } \\
\text { the association with stunting has not been adjusted for any } \\
\text { variable. } \\
\text { †Set as the reference group. } \\
\text { †Significant association at } 95 \% \text { confidence level. } \\
\text { BMI, body mass index. }\end{array}$} \\
\hline
\end{tabular}

This shows that nutrition transition is occurring and overweight/obesity is becoming a growing problem in the region.

The study results show that the combined prevalence of overweight and obesity in the subcontinent was $6.8 \%$ and 10.7 million children were affected by the problem. An earlier study also reported that, in different subregions of Africa excluding Northern Africa, the combined prevalence overweight and obesity ranged from $6.4 \%$ to $8.7 \%$ and a total of 9.3 million children were affected by the problem. ${ }^{4}$

The $6.8 \%$ prevalence of overweight/obesity reported in the subcontinent is lower than what had been estimated for the developed counties. According to a study, in 2010 the prevalence of the problem in the developed world (including Europe, Northern America, Australia, New Zealand and Japan) was $11.7 \%$ and the figure was projected to reach $12.9 \%$ by $2015 .{ }^{4}$

In four of the countries included in the study-Sierra Leone $(16.9 \%)$, Comoros (16.2\%), Malawi $(14.5 \%)$ and Mozambique $(11.9 \%)$ - the prevalence of overweight and obesity exceeded $10 \%$. Similarly, according to the 2013 global burden disease (GBD) estimate, in the aforementioned countries the prevalence in children younger than 20 years was over $10 \%{ }^{3}$ For the same set of countries, the global nutrition report also estimated relatively higher magnitude $(8-11 \%)$ of childhood overweight and obesity. ${ }^{18}$ Conversely, in Senegal, Togo and Ethiopia, the combined prevalence of overweight and 
obesity was low (2.0, 2.6 and $3.0 \%$, respectively). The estimates for these three countries by the world health statistics-2013, ${ }^{19}$ GBD-2013 ${ }^{3}$ and global nutrition report-2014 ${ }^{18}$ were also consistently low.

In developing countries, it is assumed that overweight is relatively common in urban settings and in socioeconomically privileged households. ${ }^{20}{ }^{21}$ However, this study did not witness the same. Overweight/obesity was not associated with household wealth index and place of residence. This might be partly explained by the possible rapid nutrition transition occurring in rural and urban areas and across different socioeconomic groups. Further, the methodological weaknesses of wealth index as a measure of household economic status ${ }^{22} 23$ may also partly explain the null association. Similarly, another study found that that in low and middle income countries, the difference in the prevalence of childhood overweight between the richest and poorest households was slim and the prevalence in urban and rural areas was very comparable. ${ }^{7}$

In this study, the prevalence of overweight/obesity was higher in children born to illiterate mothers than their counterparts. Two large-scale studies indicated that the increment in overweight rate is higher in poor and less educated women than in their counterparts. ${ }^{24} 25$ The finding can be due to the reason that the less educated mothers may have little information regarding a healthy diet or they may perceive higher weight gain as a healthy and desirable growth.

The study found no significant association between national GDP per capita and risk of overweight/obesity in children. Here, it is important to note that, as most of the countries included in the study are either from low or lower-middle-income categories, the data might not have adequate heterogeneity for evaluating the association. Previous studies reported inconsistent relationships. In the Caribbean and Latin America, GDP was reported to have a weak but positive correlation with prevalence of overweight ${ }^{26}$; whereas in the Organization for Economic Co-operation and Development (OECD) countries a negative association was observed. ${ }^{27}$ Other studies reported more complex patterns. ${ }^{25} 28$

The study found an association between stunting and overweight/obesity. Previous studies suggested that stunting can be a risk factor for obesity. ${ }^{29} 30$ A study based on nationally representative surveys in Russia, Brazil, South Africa and China showed significant association between stunting and overweight in all countries with a risk ratio ranging from 1.7 to $7.8 .^{30} \mathrm{~A}$ study in São Paulo, Brazil found a similar association in adolescents and younger children. ${ }^{31}$ Stunting may lower energy expenditure and impair fat oxidation to increase the risk of obesity. ${ }^{29} 32$

The findings demonstrated that low and high birth weight are associated with a lower and higher risk of childhood overweight/obesity, respectively. The relationship between macrosomia and obesity later in life is unequivocal and has been well documented. ${ }^{33-35}$
However, the relationship between LBW and obesity is arguable. The fetal origins of adult disease theory hypothesises that small size at birth is likely to be followed by rapid catch-up growth and this may increase the risk of obesity and its consequences later in life. ${ }^{36}$ However, a couple of meta-analyses found the opposite. $^{33} 34$

So far, the relationship between maternal age and childhood obesity is inconsistent. ${ }^{37}$ In this study, it is observed that risk of overweight and obesity decreased with increasing maternal age. This might be due to the reason that older mothers are likely to give birth to smaller babies ${ }^{38}$ and the weight deficit of the infants might be sustained throughout the childhood age.

The prevalence of overweight and obesity appears to be higher in children of a lower birth order. However, after adjustment was made for the number of siblings and other independent variables depicted in table 3, the association was reverted and first order births turned out to have a significantly lower risk of overweight. The relationship can be secondary to the higher susceptibility of first order births to LBW, which in turn can result in lower weight during childhood age. ${ }^{33} 34$

The study found that a smaller number of siblings is associated with increased risk of overweight and children who have no siblings have a 1.6 times increased odds of overweight compared to those who have three or more siblings. Studies conducted in Japan, ${ }^{39}$ the $\mathrm{USA}^{40}$ and Poland ${ }^{41}$ have come to the same conclusion. A smaller number of siblings might enable families to offer better nutrition, which in an extreme situation could contribute to excessive energy intake and obesity

In this study, child and maternal overweight and obesity were significantly associated. Available evidence suggests the same. ${ }^{37} 42{ }^{43}$ The relationship between maternal and childhood obesity can be linked via different mechanisms including genetic factors, shared socioeconomic characteristics and learnt behaviours including food choices and physical activity. ${ }^{37}$

The study has some important limitations. First, the finding cannot be entirely generalisable to the subcontinent, as the 26 countries included in the study might not be necessarily similar to the remaining 24 countries. Second, since the surveys were cross-sectional, causal inference is not viable. Third, the data on birth weight is prone to recall errors as its determined on the basis of the mother's recall.

\section{CONCLUSION}

With $6.8 \%$ prevalence and 10.7 million children affected, childhood overweight/obesity has become a sizeable problem in the subcontinent. In many of the countries studied, overweight is more prevalent than undernutrition. Overweight/obesity showed a significant association with stunting, birth weight and various sociodemographic variables. SSA countries should recognise 
overweight/obesity as their public health problem and interventions should be instated accordingly.

Acknowledgements The author acknowledges the Measure DHS Programme for granting access to the data.

Contributors SG conducted the data analysis and manuscript development.

Competing interests None declared.

Ethics approval For all the surveys, ethical clearance was provided by local institutional review boards and ICF Macro.

Provenance and peer review Not commissioned; externally peer reviewed.

Data sharing statement No additional data are available.

Open Access This is an Open Access article distributed in accordance with the Creative Commons Attribution Non Commercial (CC BY-NC 4.0) license, which permits others to distribute, remix, adapt, build upon this work noncommercially, and license their derivative works on different terms, provided the original work is properly cited and the use is non-commercial. See: http:// creativecommons.org/licenses/by-nc/4.0/

\section{REFERENCES}

1. World Health Organization. Diet, nutrition and the prevention of chronic diseases. World Health Organ Tech Rep Ser 2003;916:i-viii, $1-149$.

2. Lim SS, Vos T, Flaxman AD, et al. A comparative risk assessment of burden of disease and injury attributable to 67 risk factors and risk factor clusters in 21 regions, 1990-2010: a systematic analysis for the Global Burden of Disease Study 2010. Lancet 2012;380:2224-60.

3. $\mathrm{Ng} \mathrm{M}$, Fleming $\mathrm{T}$, Robinson $\mathrm{M}$, et al. Global, regional, and national prevalence of overweight and obesity in children and adults during 1980-2013: a systematic analysis for the Global Burden of Disease Study 2013. Lancet 2014;384:766-81.

4. de Onis M, Blössner M, Borghi E. Global prevalence and trends of overweight and obesity among preschool children. Am J Clin Nutr 2010;92:1257-64.

5. Freedman DS, Khan LK, Serdula MK, et al. The relation of childhood $\mathrm{BMI}$ to adult adiposity: the Bogalusa Heart Study. Pediatrics 2005;115:22-7.

6. Popkin BM, Adair LS, Ng SW. Global nutrition transition and the pandemic of obesity in developing countries. Nutr Rev 2012;70:3-21.

7. Black RE, Victora CG, Walker SP, et al. Maternal and child undernutrition and overweight in low-income and middle-income countries. Lancet 2013;382:427-51.

8. Overseas Development Institute. Future diets: obesity rising to alarming levels around the world. 2014 [cited 05 May 2015]. http:// www.odi.org/future-diets

9. Amuna $\mathrm{P}$, Zotor FB. Epidemiological and nutrition transition in developing countries: impact on human health and development. Proc Nutr Soc 2008;67:82-90.

10. Popkin BM. The nutrition transition and obesity in the developing world. J Nutr 2001;131:871S-3S.

11. The World Bank. Data: Sub-Saharan Africa (developing only). 2015 [cited 30 May 2015]. http://data.worldbank.org/region/SSA

12. Unifef. Improving child nutrition: the achievable imperative for global progress. New York: UNICEF, 2013.

13. The World Bank. Data: GDP per capita. 2015 [cited 01 June 2015]. http://data.worldbank.org/indicator/NY.GDP.PCAP.PP.CD? order=wbapi_data_value_2012+wbapi_data_value+wbapi_data_ value-last\&sort=desc

14. ICF International. Demographic and health surveys methodology. Calverton, MD: ICF International, 2012.

15. Pullum TW. An assessment of the quality of data on health and nutrition in the DHS Surveys, 1993-2003: DHS Methodological Reports No 6. Calverton, MD: Macro International Inc, 2008.

16. Population Reference Bureau. World population dataset. Washington DC: PRB, 2014.

17. Population Reference Bureau, African Population \& Health Research Center. Africa population data sheet. Washington DC: PRB, 2008.
18. IFPRI. The global nutrition report. 2014 [cited 20 May 2015]. http:// globalnutritionreport.org/the-data/nutrition-country-profiles/ country-profiles-africa/

19. World Health Organization. World health statistics 2013. Geneva: WHO, 2013.

20. Dinsa GD, Goryakin Y, Fumagalli E, et al. Obesity and socioeconomic status in developing countries: a systematic review. Obes Rev 2012;13:1067-79.

21. Martorell R, Khan LK, Hughes ML, et al. Obesity in Latin American women and children. J Nutr 1998;128:1464-73.

22. Howe LD, Hargreaves JR, Huttly SR. Issues in the construction of wealth indices for the measurement of socio-economic position in low-income countries. Emerg Themes Epidemiol 2008;5:3.

23. Howe LD, Hargreaves JR, Gabrysch $S$, et al. Is the wealth index a proxy for consumption expenditure? A systematic review. $J$ Epidemiol Community Health 2009;63:871-7.

24. Ziraba AK, Fotso JC, Ochako R. Overweight and obesity in urban Africa: A problem of the rich or the poor? BMC Public Health 2009;9:465.

25. Jones-Smith JC, Gordon-Larsen P, Siddiqi A, et al. Is the burden of overweight shifting to the poor across the globe? Time trends among women in 39 low- and middle-income countries (1991-2008). Int J Obes (Lond) 2012;36:1114-20.

26. Duran $\mathrm{P}$, Caballero $\mathrm{B}$, de Onis $\mathrm{M}$. The association between stunting and overweight in Latin American and Caribbean preschool children. Food Nutr Bull 2006;27:300-5.

27. Loureiro ML, Nayga RM. International dimensions of obesity and overweight related problems: an economics perspective. Am J Agric Econ 2005;87:1147-53.

28. Egger G, Swinburn B, Islam FM. Economic growth and obesity: an interesting relationship with world-wide implications. Econ Hum Biol 2012;10:147-53.

29. Sawaya AL, Roberts S. Stunting and future risk of obesity: principal physiological mechanisms. Cad Saude Publica 2003;19(Suppl 1): S21-8.

30. Popkin BM, Richards MK, Montiero CA. Stunting is associated with overweight in children of four nations that are undergoing the nutrition transition. J Nutr 1996;126:3009-16.

31. Sawaya AL, Dallal G, Solymos G, et al. Obesity and malnutrition in a Shantytown population in the city of São Paulo, Brazil. Obes Res 1995;3(Suppl 2):107s-15s.

32. Hoffman DJ, Sawaya AL, Verreschi I, et al. Why are nutritionally stunted children at increased risk of obesity? Studies of metabolic rate and fat oxidation in shantytown children from São Paulo, Brazil. Am J Clin Nutr 2000;72:702-7.

33. Schellong K, Schulz S, Harder T, et al. Birth weight and long-term overweight risk: systematic review and a meta-analysis including 643,902 persons from 66 studies and 26 countries globally. PLoS ONE 2012;7:e47776.

34. Zhao Y, Wang SF, Mu M, et al. Birth weight and overweight/obesity in adults: a meta-analysis. Eur J Pediatr 2012;171:1737-46.

35. Rossi CE, de Vasconcelos F. Birth weight and obesity in children and adolescents: a systematic review. Rev Bras Epidemiol 2010;13:246-258.

36. Delisle PH. Programming of chronic disease by impaired fetal nutrition: evidence and implications for policy and intervention strategies. Geneva: WHO, 2002.

37. Saunders T. Potential contributors to the Canadian pediatric obesity epidemic. ISRN Pediatr 2011;2011:917684.

38. Kramer MS. Determinants of low birth weight: methodological assessment and meta-analysis. Bull World Health Organ 1987;65:663-737.

39. Ochiai $H$, Shirasawa T, Ohtsu T, et al. Number of siblings, birth order, and childhood overweight: a population-based cross-sectional study in Japan. BMC Public Health 2012;12:766.

40. Chen AY, Escarce JJ. Family structure and childhood obesity: an analysis through 8th grade. Matern Child Health $J$ 2014;18:1772-7.

41. Mazur A, Klimek K, Telega G, et al. Risk factors for obesity development in school children from south-eastern Poland. Ann Agric Environ Med 2008;15:281-5.

42. Modi N, Murgasova D, Ruager-Martin R, et al. The influence of maternal body mass index on infant adiposity and hepatic lipid content. Pediatr Res 2011;70:287-91.

43. Jimenez-Cruz A, Wojcicki JM, Bacardi-Gascon M, et al. Maternal BMI and migration status as predictors of childhood obesity in Mexico. Nutr Hosp 2011;26:187-93. 